\title{
My Critique is Bigger than Yours: Constituting Exclusions in Critical Security Studies $^{1}$
}

\author{
DAVID MUTIMER \\ York Centre for International and Security Studies, York University
}

\begin{abstract}
Critical Security Studies proceeds from the premise that words are world-making, that is that the ways we think about security are constitutive of the worlds of security we analyze. Turned to conventional security studies and the practices of global politics, this critical insight has revealed the ways in which the exclusions have been produced. Perhaps most notable in this regard has been David Campbell's work, showing how the theory and practice of security are an identity discourse producing both insides and outsides, but the production of excluded others is a theme that runs through the critical scholarship on security in the past decade or more. This article turns the critical security studies gaze on itself, to explore the field's own complicity in the production of exclusions. The article reads three important instances of critical security studies for the inclusions and exclusions they produce: Ken Booth's Theory of World Security, the epilogue to David Campbell's Writing Security, and the CASE Collective Manifesto. The article concludes by asking about the nature of the inclusions and exclusions these divisions produce and the politics which those exclusions, in turn, (re)produce.
\end{abstract}

Critical Security Studies should know something about exclusion.

While the character of Critical Security Studies is the subject of some considerable debate, there would be broad agreement that the nature and purposes of exclusion are at its heart. Whether framed in terms of inside and outside, self and other, domination and oppression, or termed directly inclusion and exclusion, the production of a zone of security and the necessity of both an exclusion from that zone and a borderland where the secure meets its other are at the very heart of any work that would lay claim to the Critical Security Studies label. Critical Security Studies began with the recognition that the traditional approach to security masked the socially produced nature of these divisions. Security was considered "natural," and yet who was secured, from what, and by what means, were radically contingent. The first steps of Critical Security Studies was to reveal that contingency and the 
social practices that made it possible, and as such, necessarily, raised questions of exclusion.

The traditional answers to the question of who was secured, from what and by which means were simple and widely understood: security concerned the preservation of the state from external threats by military means. These answers rested on a prior set of answers that were less well known, but not tremendously controversial once revealed: security was ultimately about protecting "people," but the state was the means to providing that protection, and as the only thing that could (existentially) threaten the state was external military power, we could largely forget people and concentrate on the security of the state from military threats. As Keith Krause and Michael Williams noted in the first book titled with Critical Security Studies, "The [conventional] vision of security effectively makes it synonymous with citizenship. Security comes from being a citizen, and insecurity from citizens of other states” (Krause \& Williams, 1997b, p. 43). To the degree that is true, however, security is necessarily predicated on a dual exclusion: the first is the citizen from citizens of "other" states, and the second is the citizen from the non-citizen. ${ }^{2}$

So, from its outset, Critical Security Studies has been concerned with the way in which security produces an included (citizen) and an excluded (other- or noncitizen). For the majority of its practitioners, however, the concern with exclusion is far more extensive than this initial exclusion constituted around citizenship, as important as that may be. Krause and Williams initially eschewed the temptation to characterize the "critical" in Critical Security Studies as anything more than a vague orientation: "Our appending of the term critical to security studies is meant to imply more an orientation toward the discipline than a precise theoretical label . . ." (Krause \& Williams, 1997c, pp. x-xi). Most who have followed them, however, would adopt a slightly more demanding notion of social critique. Ken Booth, for instance, has tried to capture the nature of "critical" in a manner that a range of theoretical positions would accept: "Critical theorizing does not make a claim to objectivity but rather seeks to provide deeper understandings of oppressive attitudes and behaviour with a view to developing promising ideas by which human society might overcome structural and contingent human wrongs” (Booth, 2007, p. 30). Put more simply, at some level Critical Security Studies is committed to a politics of emancipation(s), and so is concerned not only with identifying forms of exclusion but with overcoming them. ${ }^{3}$

You might think, therefore, that with a project predicated on revealing the production of exclusion as a condition of oppression, and a politics committed to overcoming the oppressions produced by exclusions, Critical Security Studies would not be a field in which exclusions are (re)produced. You would be wrong.

In this article, I explore the exclusions that are being produced in the Critical Security Studies literature. I begin by locating the production of exclusion in three key texts of the Critical Security Studies tradition. The first is Ken Booth's Theory of World Security, a text that aims to provide an emancipatory security theory. Booth's book, and his other work, are located within the tradition of critical scholarship that can be called "German" or perhaps "post-Marxist." The second text I will read hails from the second major strand of critical theorizing, the "French" or "post-structural," and is the Epilogue to the second edition of David Campbell's Writing Security. The book is centrally concerned with exclusion, as it is an exploration of the production 
of the United States through discourses of fear, which necessarily place some "Other(s)" as the threatening outsider. In the Epilogue to the second edition, Campbell turns his attention from Foreign Policy to disciplinary politics. Having considered the ways in which exclusions are effected in both major strands of critical theorizing, I turn to a text that explicitly seeks to work across them: "The Critical Approaches to Security in Europe (CASE) Collective Manifesto.” The Manifesto is a collective effort that seeks to bridge the gaps that are emerging in the critical study of security, at least in Europe. In the third section of the article, I examine that effort, and the raft of exclusions this explicitly inclusionary exercise has produced.

The Critical Security Studies literature accepts the "world-making" ability of words, or put another way, understands the scholarly enterprise to be necessarily political. Regardless of the theoretical tradition informing the critique of Critical Security Studies, its authors would accept that the exclusions that are (re)produced in the pages of critical security texts do work in the (re)production of exclusions beyond those pages. Having examined those exclusions in three key texts in the literature, I turn in the final section to ask questions of that politics. Why does it matter that exclusions are (re)produced in the pages of Critical Security Studies texts?

\section{Selectively Diving for Pearls Ken Booth's Theory of World Security ${ }^{4}$}

Ken Booth is perhaps the leading figure in Critical Security Studies, and his 2007 text, Theory of World Security, is the most complete statement to date of his views on questions of security, theory, and world politics. Indeed, Booth describes the book as the culmination of a thirty year project, which began with an early version of what became 1979's Strategy and Ethnocentrism (Booth, 2007, pp. xvii-xviii). Theory of World Security is a work of truly impressive scope, aiming to "explain and advance a case for a particular theoretical framework with which to explore and engage with the security of real people in real places" (Booth, 2007, p. xii). The theoretical framework, the "theory of world security" of the title, is informed by the "emancipatory realism"5 that Booth has been developing for more than the past decade, and is applied in the text to the broad sweep of contemporary world politics. Booth aims to illuminate a "new 20 years crisis" we are entering, that he feels will culminate in the "Great Reckoning"-a concatenation of a series of profound challenges to world politics. His central thesis is that to respond to that crisis we need a critical theory of world security, as only emancipation can produce true security. ${ }^{6}$

In his recent work, building to his statement of a critical security theory, Booth has been explicit on grounding that work in the tradition of post-Marxist thought in general, and the Frankfurt School in particular. In Theory of World Security, while retaining his intellectual debt to this tradition, Booth seeks to be both broader and more eclectic in his theoretical presuppositions. He adopts an approach he calls “perlenfischerei” (pearl fishing), following from Hannah Arendt (Booth, 2007, p. 3840). He plucks pearls from a range of sources to string together his theoretical necklace, though the work loses more in coherence of approach than it gains in its eclecticism. Nevertheless, the central theoretical commitments of the text are clear. 
Booth explicitly seeks to reclaim the enlightenment project of reason and progress (Booth, 2007, p. 116-33), informed by a commitment to a communitarian future which owes much to the vision of Jurgen Habermas and his student in IR, Booth's colleague at Aberystwyth, Andrew Linklater (Booth, 2007, p. 40-58).

There is one oyster bed into which Booth refuses to dive in search of his theoretical pearls, however, and readers of his work in the past decade will not be surprised to learn that it is post-structuralism, for, as he writes: "postmodern approaches (as they generally do not like to be known) are invariably obscurantist and marginal, providing no basis for politics ...” (Booth, 2007, p. 468). The passage is quite remarkable for its recapitulation of so many of the problems in the treatment of approaches to security which draw on the generally French thinkers of the poststructural. First of all, if "they" generally do not like to be known as postmodern, who are the "they" that are captured by the label? The answer might be apparent if any of the scholars whose work Booth dismisses were discussed, but they are not. So, how do we know that they are all invariably obscurantist? (Perhaps because the label is one applied by Booth rather than by the authors, he includes only those that are?)

Furthermore, how do we judge the lack of a basis for politics? Booth's politics is based, in part, on an ethics which begins from the face-to-face (though he refers to it only in passing), and yet he does not engage with the range of scholarship that has been thinking for the past decade about the ethics of world politics beginning from Levinas' conception of the face-to-face (Campbell, 1995; Campbell \& Shapiro, 1999; Dauphines, 2008; Edkins, 2003; Lisle, 2006). Indeed, it is well worth wondering how Booth can dismiss the capacity for a politics without engaging, at least, with those trying to develop just such a politics. The most significant such example is David Campbell's National Deconstruction (Campbell, 1998b, p. 165244). While not all would agree with his argument, it seems strange that Booth would not engage with a notion of multiculturalism in the context of a "democracy that is to come" which seems, superficially at least, similar to his own ideas on cosmopolitanism and the goal of democracy.

It seems likely, on the evidence of the text, that Booth is aware of the problems of a critical theory effecting the sort of exclusion that he performs in relation to poststructural literature. In looking to the future of security studies writ large, he argues: "But to argue for the primacy of a critical theory of security is not to argue for disciplinary totalitarianism. Such would be contrary to the nature of the critical project. Furthermore, intellectual pluralism is desirable in order to keep everybody honest. Tomorrow's security studies should be pluralistic, and informed by accessibility, relevance, and engagement” (Booth, 2007, p. 462). He continues to give examples of the breadth of such an accessible, relevant and engaged security studies:

Since the late 1970s, the agenda of academic theorizing in international relations has broadly been established by the neo-realism inspired by Kenneth Waltz's Theory of International Politics. His book was an exercise in "parsimonious" theorizing, and remains the discipline's apogee in that regard. There is a role for parsimonious theory, but only a limited one, in saying a few big things about a big issue (Booth, 2007, p. 463).

Studies in Social Justice, Volume 3, Issue 1, 2009 
It would appear, therefore, that the pluralist scope of security studies is expansive enough to include Waltz's neo-realism and its explicitly statist agenda (if only in a small way, to say some "big" things). Booth's concession is quite monumental in the context of a field of study that has developed from opposition to the very realism of which Waltz is the parsimonious apogee. Despite his expansive conception of security studies, there is no place for the post-structural.

Booth, then, effects an impressive and impermeable exclusion in Theory of World Security. ${ }^{7}$ His theory is eclectic, but intentionally restrictive. He is not setting out to define a field of security studies, but rather to provide a specific theory of security in the contemporary context. As such, he builds from a range of post-Marxist scholarship, and supplements it with ideas he takes from where he can find them. As only one theory, however, he recognizes that it should not be considered exhaustive or even exclusive in its commentary on contemporary security. However, while the nearly full range of alternative theorizing is accepted, the post-structural (or "postmodern" as they generally do not like to be called) are excepted. There is a clear, glowing intellectual line in Booth's thought, and (only?) post-structuralism is placed outside.

\section{Border Politics ${ }^{8}$ \\ The Epilogue to Campbell's Writing Security}

Booth produces a boundary by which to exclude the post-structural, but what happens within that bounded, excluded space? I now turn to that question, inquiring into the exclusions produced by post-structural writing on security. Within the disciplinary politics of International Relations, there are few positions that have been more aggressively and systematically excluded than the post-structural. Booth's antagonism to those who have derisively been described as "french fries" is far from unique; it is only surprising inasmuch as it fits so badly with his own expressed theoretical and disciplinary preferences. Indeed, both Booth's basic opposition-that there is no possibility for a post-structural politics - and his apparent pluralism in letting ninety-nine flowers bloom, echo the loudest disciplining voices over the past two decades. Post-structural writing on security, therefore, should be the most sensitive to the nature and power of exclusionary practices, on at least two levels. The work itself has been centrally concerned with the politics of "othering," while at the same time being identified as everyone's other.

David Campbell's work has been at least as significant as Booth's, both inside and outside the study of security. In this section, I read one small instance of Campbell's work, the Epilogue to the $2^{\text {nd }}$ Edition of Writing Security, to explore the ways in which he too produces exclusions. Writing Security is a study of the production of the United States through a discourse of fear. Campbell shows how two "foreign policies"-the capitalized Foreign Policy we are used to discussing in International Relations and a lower-case foreign policy working both domestically and internationally to "make foreign" (Campbell, 1998a, p. 35-38)—work together to produce dangerous "others," and how the US constitutes itself in then opposing these "others." It is a book, therefore, that is centrally concerned with the production and effects of the security exclusions that are the starting point for this article. 
In the Epilogue, Campbell turns his attention from US Foreign Policies to the politics of the discipline of International Relations. Indeed, a primary motivation for the Epilogue is precisely in the disciplinary exclusions that had been effected against post-structural work in the decade before it was written:

The contingency and flux of the post-cold war period has provided a moment that furthered the cause of already existing critical theories, and triggered a pluralization of critical approaches in international relations.... In this epilogue, I want to explore the disciplinary politics evident in the reaction to these changes. Specifically, I want to consider the growth in international relations' scholarship dealing with questions of political identity since Writing Security was first published, and the way the disciplinary reaction is a form of discipline that renders the new as “foreign” and “dangerous” (Campbell, 1998a, p. 209).

Campbell begins with a defence against the mainstream abhorrence of post-structural work, but, as he notes, the requirements for defence have lost some of their urgency: "Where once the above objections to the impoverished understanding of "postmodernism" in international relations would have been made in a defensive mode, now they are put forward with an air of resigned exasperation" (Campbell, 1998a, p. 215). In other words, even by 1998, post-structural work was well enough established that the gatekeepers were left, as he puts it: "observed in the rearview mirror waving their arms wildly and still demanding their papers and price of admission" (p. 215). Thus, with the fight against the mainstream gatekeepers appearing largely to be won, Campbell takes on more difficult targets: first the "modernist constructivism" of Alexander Wendt and others, and then the constructivism "deployed by critical scholars sometimes intellectually allied with poststructuralism” (p. 222).

Campbell considers the conventional constructivists through a reading of the development of Wendt's work, together with a discussion of a leading constructivist volume on security, the 1996 book The Culture of National Security (Katzenstein, 1996). His central criticism is that:

\begin{abstract}
What we are witnessing in arguments such as [these], therefore, is little more than an attempt to domesticate "discourse" and related notions, so that the substantive interests of critical scholars can be mapped onto the preexisting strictures of empirical social science, while the larger metatheoretical (and thus ethico-political) questions of their positions can be avoided (Campbell, 1998a, p. 218).
\end{abstract}

The "constructivist” work, therefore, attempts a marginalization of the post-structural in many ways more potent than the mainstream's outright dismissal. The work of those like Katzenstein and Wendt draw in the post-structural concerns of culture and identity, and even some of the language of post-structural writing, without altering the epistemological or even, to any great degree, the ontological assumptions of conventional International Relations scholarship: “Indeed, Wendt's self-professed modernist constructivism . . reendorses state-centric realism, with its implications of volitional agents, while marginalizing a more radical understanding of identity” (Campbell, 1998a, p. 219). 
What of the second group of constructivists Campbell identifies, those fellowtravellers “intellectually allied with poststructuralism”? Here Campbell treads carefully, but still seeks to draw a clear line between this form of constructivism and post-structuralism:

To draw distinctions between poststructuralists and critical constructivists goes against an increasingly common tendency .... It is also a distinction which in the first instance is difficult to make and contentious to suggest, not least because much critical work combines in a productive way the different positions (Campbell, 1998a, p. 223).

Despite these difficulties, he continues to draw the distinction because it yields an important theoretical point. The critical constructivists stop at the final point at which the post-structural break with the modernist constructivists is complete, seeking to retain an acting subject in some sense independent of the discourses and practices which it constructs. The problem with this philosophical hesitation, Campbell concludes, is that "critical constructivist arguments can be more easily drawn into the realm of judgment where the protocols of "empirical social science" rule, to the detriment of a politicized account of important practices” (Campbell, 1998a, p. 225).

The argument Campbell develops in the Epilogue is sophisticated and nuanced, rather more than my short account can capture. The effect of his discussion, however, is to develop a graded series of inclusions and exclusions:

1. At the extreme (either outside or inside depending on your vantage) is the mainstream, which adheres to the protocols of empirical social science, including a rigid separation of subject and object, and an ontological commitment to the primacy of the state in world politics. In terms of disciplinary politics, these are the gatekeepers who have so vigorously opposed the introduction of continental social theory into the study of international relations.

2. Next are the modernist constructivists, who accept the empirical importance of "culture" but provide an analysis of social construction by means of extra-discursive agents who engage in "construction." Campbell sees these scholars and their work as dangerous because they adopt the language of identity and social construction, but they do so in a way that actually reproduces the static, statist agenda of the mainstream.

3. If the modernists are on the side of the mainstream, raiding across the border to the substantive concerns of the post-structuralists (Campbell, 1998a, p. 216), then the critical constructivists occupy the boundary space between the mainstream and their constructivist allies and the poststructuralists. In some ways the critical constructivists are perhaps even more dangerous than the modernists, as they openly ally with the intellectual politics of post-structuralism, but in a way that can reinforce the exclusions of the mainstream.

4. Finally, at the other extreme (again outside or in) are the post-structuralists, who pursue the philosophical and political implications of the performative constitution of identity, in which "there is no power, constructed as a subject, that acts, but only . . . a reiterated acting that is power in its persistence and stability” (Judith Butler, as cited in Campbell 1998a, p. 224). 
What is Campbell's purpose in drawing these fine distinctions, particularly the last between the post-structural and critical constructivist? It "is to enable a better response to the mainstream appropriations” (Campbell, 1998a, p. 225). In other words, he seeks to draw a hard and fast line between the post-structural and modernist constructivist positions, and invites those in the margins to get on the right side of the line! Even in a text that explores so well the dangerous political consequences of producing difference as exclusion, written from a position that has felt the power of being excluded, exclusions are produced and policed. Does Critical Security Studies have no answer to these repeated exclusions? The next section considers the work of a group of scholars who tried to answer this question in the affirmative.

\section{Manifest Exclusions \\ The CASE Collective’s “Networked Manifesto”}

In 2006, Security Dialogue published an article that was rather unusual in the canon of security studies, and indeed of the social sciences more broadly. It was unusual in at least two senses. The first was that the author was identified as the "CASE Collective." CASE stands for Critical Approaches to Security in Europe, and the Collective is just that, a group of scholars writing collectively. While it is not uncommon for a number of authors to collaborate on a text, there tend to be two, three or at times four; the CASE Collective numbered twenty-five. Also, the usual way of identifying collective authorship is to list the authors as authors; the CASE Collective identifies the Collective as the author, and then lists its membership in a footnote. ${ }^{9}$

The second sense in which the article is unusual is in its use of the term "Manifesto." Manifestos are intensely partisan documents, issued by governments or political parties to outline and justify policies or platforms. ${ }^{10}$ While critical theory is attuned to the political nature of all scholarship, it is not common for a scholarly paper to be labelled so overtly politically. The politics the Collective was pursuing is set out in the first few pages:

[T] he aim of working and writing as a collective, a network of scholars who do not agree on everything yet share a common perspective, is based on a desire to break with the competitive dynamic of individualist research agendas and to establish a network that not only facilitates dialogue but is also able to speak with a collective voice (CASE Collective, 2006. p. 444).

The goal of the Collective, therefore, is to overcome the divisions that have riven critical approaches to security (in Europe), including those that divide the postMarxist work of Booth and his colleagues and the post-structural work of Campbell and his:

The authors share the view that, over the past two decades, important innovations in the study of "security" have emerged among European scholars in particular. Although the genesis of these innovations involves scholars on both sides of the Atlantic, these approaches have arguably

Studies in Social Justice, Volume 3, Issue 1, 2009 
gained momentum and density in Europe, leading to the emergence of distinctive European research agenda(s) in the traditionally US-dominated field of "security studies." Consequently, it was felt that the time had come to evaluate these "European" approaches, both in order to increase their exposure and to push them further in specific directions (CASE Collective, 2006, p. 444).

Indeed, the Manifesto is explicit in both naming three "schools" of thought and undermining their meaningfulness: schools they term "Copenhagen," "Aberystwyth," and "Paris." The first refers to those developing the ideas of "securitization" that were originally articulated by Ole Waever, of the University of Copenhagen, and then married to the sectoral approach to security of Barry Buzan (Buzan, Waever, \& de Wilde, 1999). The second refers to Booth and his colleagues, centred on the Department of International Politics at Aberystwyth University. The Paris school is broadly post-structural, though has the same eclecticism as is evidenced throughout the literature identified in this fashion. The city label refers to the importance of Didier Bigo at Sciences-Po in Paris. "The aim of the CASE Collective is precisely to go beyond the artificial boundaries [of the three schools] in order to combine a variety of critical approaches under a common framework, without, nonetheless, reducing one approach to another” (CASE Collective, 2006, p. 451).

The Manifesto is, therefore, extraordinary in its attempt to be inclusive, explicitly aiming to construct a productive network across approaches that have overtly excluded one another in the past, and that, in some cases, are based on fundamentally different notions of the nature of security and of science. I have shown above how Booth works to ensure that post-structuralism is outside the pale. As for the Copenhagen approach, in its most extensive elaboration, Security: A New Framework for Analysis, it is at pains to distinguish its framework from both a constructivist Critical Security Studies, and a post-structural approach to security. Both constructivism and post-structuralism, the Copenhagen authors argue, are committed to the prospect of social change, and embrace both epistemology and ontology that are at odds with those of Copenhagen:

\begin{abstract}
Although our philosophical position is in some sense more radically constructivist in holding security to always be a political construction and not something the analyst can describe as it "really" is, in our purposes we are closer to traditional security studies, which at its best attempted to grasp security constellations and thereby steer them into benign interactions. This stands in contrast to the "critical" purposes of CSS, which point toward a more wholesale refutation of current power wielders (Buzan et al., 1998, p. 35).
\end{abstract}

The Copenhagen approach considers the structures of international social life to be sufficiently sedimented that they can be treated as if they were objective (hence in keeping with traditional security studies and opposed to the "critical purposes" of critical security studies) (Buzan et al., 1998, p. 34-35).

In the Manifesto, then, we might expect to find no production of exclusions, for the Collective is taking its exclusions as given and working to overcome them. Quite remarkably, however, in a series of responses to the text that were published in the 
subsequent volume of Security Dialogue, the Collective was taken to task precisely for the exclusions it served to effect. Andreas Behnke (2007) argues that the Collective violates the critical project in the closures it effects:

One of the strengths of CSS is its loose boundaries, multifaceted nature and constant productivity. In this sense, the manifesto's intent to define insiders and outsiders, both geographically and personally, is a highly problematic move. Yet, this move can be understood in terms of a manifesto's need to impose closure upon truth and to keep what is in the shadows from view. The manifesto at hand engages two topoi, "place" and "author," to engender this closure (p. 106).

Behnke's primary concern is with the second of his two topoi, the "author." Specifically, he shows how the Collective's personalization of the history of CASE in particular and Critical Security Studies in general hides their constitutive intellectual traditions, which in turns enables the exclusion of some. In particular, he is concerned with the excision of Carl Schmitt: "Perhaps the most disappointing aspect of the manifesto is its treatment of one of the constitutive contributions to its critical philosophy. The dismissal of Carl Schmitt's work on the political and the exception forecloses a proper investigation of the processes of depoliticization that are rightly at the heart of the CASE agenda” (Behnke, 2007, p. 108).

In terms of place, Behnke is concerned with the way a line is drawn around "Europe," a concern that is picked up in a second response by Mark Salter: "To what extent does the collective wish to be tied to the continental metaphor of 'Europe'?" (Salter, 2007, p. 114). Behnke notes the ambiguity of the geographic inclusion / exclusion, wondering if ultimately it refers to the citizenship or home base of the scholars in question. "In either case, it is an undue and peculiar exclusionary move that in fact expresses an epistemic ontopology counter to the professed network character of the CASE collective. Networks, after all, are notorious for transcending boundaries" (Behnke, 2007, p. 106). Salter notes the strange position of Canada in the world that CASE produces, by opposing critical Europe to American-dominated security studies (Salter, 2007, p. 116-17). As he notes, the research program at the heart of the "Paris" School is jointly run by Didier Bigo out of Paris and RBJ Walker out of either the Universities of Victoria (Canada) or of Keele (UK), depending on the time of year. Canada is too small for Canadian scholars to be insularly Canadian, and many seek their primary intellectual and professional ties in Europe, and yet they are excised from the CASE universe by that final "E."

Salter does not stop there, however, posing two further questions of exclusion to the Collective: "To what extent does the collective want to define the limits of the CASE endeavour? And to what extent does the collective intend to police its membership, through the approval or disavowal of specific kinds of scholarly and political interventions?” (Salter, 2007, p. 114). He then explores these questions, with particular reference to the post-colonial and development studies-both excluded from the CASE Collective's apparent ambit-and asks a difficult question of central importance to the question of inclusion and exclusion:

Where does the collective end, or will all disciplines be assimilated? The paradox with this kind of expansion is that the collective must choose in 


\begin{abstract}
some sense between a description of assumptions and problems that are common and non-negotiable, or a more amorphous concern with general issue-areas. The former risks alienating some scholars and potential partners; the latter risks starting an endless debate as to what constitutes the field (Salter, 2007, p. 117).
\end{abstract}

In other words, while Salter contests some of the exclusions CASE effects, and particularly laments the evident policing in which they seek to engage, he suggests that some exclusion is necessary. I return to the question of the necessity of exclusion in the conclusion.

In some ways the most startling of the responses to the Collective's Manifesto was that published three issues after Behnke's and Salter's. In her piece, Christine Sylvester (2007) produces a close reading of one footnote of the Manifesto to show how the Collective has excised certain forms of scholarship, while valuing others. In particular, the footnote excludes from the Collective "hard-core postmodernists" and "feminists" (p. 549). Sylvester takes up the question of the exclusion of feminism from the CASE network, focussing in particular on the work of Lene Hansen. Hansen is indeed mentioned in the footnote Sylvester analyses, as the author of interesting work not included in the Collective (together with four others, three of whom are Canadian!) Sylvester asks what it means to exclude the writing of a leading post-structural feminist scholar, whose work is clearly "critical" and concerned with "security"? The question is particularly pointed in the case of Hansen, for not only has she written a widely-cited piece on the exclusion of feminism from the Copenhagen School (Hansen, 2000), but actually works at the University of Copenhagen: "That she works in Copenhagen could make her part of the Copenhagen School; but, given that the collective takes pains to avoid drawing too literal a line under place-names, it might just be that she does critical security studies but not in approved School ways” (Sylvester, 2007, p. 551).

The overtly inclusive exercise of critical network building, then, seems to produce even more exclusions than the earlier texts that were explicit in their exclusions. The Collective's "European-ness" serves to exclude Canadians (and, presumably, Australians and others), although it might be possible to breach this boundary by moving (even part-time) to "Europe.” Perhaps even more troubling, the tripartite form of the "Schools," together with an all-too rigid understanding of what fits within them, works to exclude forms of (critical) scholarship from the privileged European core: Schmitt and those working from him are out, as are "hard-core postmodernists" and (at least some) feminists even if they happen to be European, and even when they work in Copenhagen or Aberystwyth.

\title{
Conclusion \\ Kept from Dancing on the Pin's Head
}

To conclude, I want to ask why this all matters. I have outlined a series of exclusions that are produced in the pages of books and journals that, if we are to be honest, are read by very few - in the grand scheme of things, at least. Am I not simply taking a new angle on a very old characterisation of philosophical futility (originality!), and seeing which angels are not dancing on the pin's head? 
Most critical scholarship in International Relations begins, in some sense, from Robert Cox's observation that all theory is for someone and for some purpose. (Cox, 1986, p. 207) It is rarely noted that this means, necessarily, that theory is also against someone and against their purposes. While rarely noted, it would generally not be seen as overly problematic by critical theorists if it were, because the assumption is that critical theory is for the oppressed, for the excluded, and is therefore against the oppressor, against those on the inside keeping the deserving out. But who are the deserving? Our reflex is that they are any that are kept out, but here is the point at which the discussion I have just followed gains its significance. The various forms of critical theorizing about security identify those deserving by identifying whom it is their theory is for. By effecting exclusions from the critical project, the different forms of theorizing produce some as doubly excluded: they are outside, but not deserving. Emancipatory critical theory is revealed to be against not only the oppressors, those inside guarding the gates, but against some of those on the outside as well. As Christine Sylvester puts it:

When critical people of all persuasions and locations forget to recognize
that critical comes in many forms, when they designate some critical
analysts as 'other participants', fall into the habit encouraged by camp IR
to focus narrowly and rally around a few thinkers, when they forget that
feminists are dissidents too and that women are in security peril the world
round ... they are in trouble..." (Sylvester, 2007, p. 556)

The conclusion is unavoidable, then, that each of the positions I have surveyed is "in trouble," as each effects just such exclusions of other forms of critique and the insecure outsiders for whom those others speak. Booth's post-Marxism privileges those excluded on the basis of class, but the disparagement of post-structuralism effects an excision of not only the writers but the varied forms of identity for whom they write. These multiple and overlapping forms of identity include, but are not limited to, those constituted by race, sexual orientation and, of course, gender. The CASE Collective, even in its aim to be inclusive, excludes feminists and the insecure women for whom they write, as well as the non-Europeans who may also write for subjects other than those that are the focus of European authors.

The question that remains, of course, is whether we can escape the production of exclusions in our attempts at critical (security) scholarship. My answer is that no, we cannot. By speaking for some we necessarily speak against others, and the range of those who face oppression, those for whom critical scholarship is written, is too great for them all to be written for at once. My corollary to this observation is that there will be different outsiders who most need critical theory at different times and in different places. In taking this step, I make clear my own choice amongst the inclusions and exclusions I have surveyed, for from this corollary follows a poststructural critical ethos. While we cannot avoid effecting exclusions in our work, we can resist the temptation to effect them a priori. Rather, we need to turn our critical gazes constantly on ourselves to ask if, at each time and in each place, we are theorizing for those most in need. Doing so acknowledges that other outsiders will be excluded by our choices, but has at least the benefit of doing so in a limited and contingent fashion. 


\section{Notes}

1 A previous version of this article was presented at the workshop: "Security and Exclusion," Centre for Social Justice, University of Windsor, and October 23, 2008. I would like to thank the participants for their comments and suggestions, which made for a better piece; the problems that remain are, of course, mine alone!

2 The importance of this primary exclusion has, of course, been dramatically highlighted in the years since 9/11. The protection a state owes its citizens, for example, led to Maher Arar's "rendition" to Syria for torture rather than the return to Canada he (by right) demanded. On the other side, the near Medieval "security certificates" that the Supreme Court has only recently reined in, are applicable only to the non-citizen.

3 For a discussion of Critical Security Studies in the context of a commitment to progressive politics and emancipation(s), see Mutimer (forthcoming 2009).

4 Parts of the following discussion of Booth's text have been published in a different form as Mutimer (2008).

5 Booth has been using the term "Utopian Realism" for his approach to security for some time, but has "become resigned to thinking that the label is unhelpful: 'utopia' is an idea with too much negative baggage, and in any case smacks too much of a static blueprint" (Booth, 2007, p. 90).

6 The relationship between emancipation and security has been central to Booth's thinking, and his contribution to the development of Critical Security Studies, since its early articulation in Booth (1991).

7 This is not a new exclusion for Booth. See, for example, Booth (2005a).

8 The title is taken from the first section heading in the Epilogue (Campbell, 1998a, p. 207).

9 The Collective appears serious about the collective nature of the enterprise, as the Rejoinder piece published the next year under its name identified only 16 authors, and some had not been part of the original Collective. (CASE Collective, 2007).

${ }^{10}$ The most famous Manifesto, of course, is the Communist Manifesto of Marx and Engels. More mundane, though no less partisan, the electoral programs of the British political parties are known as their manifestos.

\section{References}

Behnke, A. (2007). Presence and creation: A few (meta-)critical comments on the C.A.S.E. manifesto. Security Dialogue, 38(1), 10511.

Booth, K. (1979). Strategy and ethnocentrism. London: Croom Helm.

Booth, K. (1991). Security and emancipation. Review of International Studies, 17(4).

Booth, K. (Ed.). (2005). Critical security studies and world politics. Boulder: Lynne Rienner.

Booth, K. (2005a). Beyond critical security studies. In K. Booth (Ed.), Critical security studies and world politics. (pp. 259-278). Boulder: Lynne Rienner.

Booth, K. (2007). Theory of world security. Cambridge: Cambridge University Press.

Buzan, B., Waever, O. \& de Wilde, I. (1998). Security: A new framework for analysis. Boulder: Lynne Rienner.

Campbell, D. (1998a). Writing security: United States foreign policy and the politics of identity ( $2^{\text {nd }}$ ed.). Minneapolis: University of Minnesota Press.

Campbell, D. (1998b). National deconstruction: Violence, identity and justice in Bosnia. Minneapolis: University of Minnesota Press.

Campbell, D. (2002). Atrocity, memory, photography: Imaging the concentration camps of Bosnia-The case of ITN versus living Marxism. Journal of Human Rights, 1(1), 1-33 \& 1(2), 143-172.

Campbell, D. \& Shapiro, M. (Eds.). (1999). Moral spaces: Rethinking ethics and world politics. Minneapolis: University of Minnesota.

CASE Collective. (2006). Critical approaches to security in Europe: A networked manifesto. Security Dialogue, 37(4), 443-87.

CASE Collective. (2007). Europe, knowledge, politics: Engaging the limits: The CASE Collective responds. Security Dialogue, 38(4), 559-576.

Cox, R. (1986). Social forces, states and world orders: Beyond international relations theory. In Robert Keohane (Ed.), Neorealism and its critics (pp. 204-254). New York: Columbia University Press. 
Dauphines, E. (2008). The ethics of researching war: Searching for Bosnia. Manchester: Manchester University Press.

Edkins, J. (2003). Trauma and the memory of politics. Cambridge: Cambridge University Press.

Hansen, L. (2000). The Little Mermaid's silent security dilemma and the absence of gender in the Copenhagen School. Millennium: Journal of International Studies, 29(2), 285-306.

Katzenstein, P. (1996). The Culture of national security norms and identity in world politics. Ithaca: Cornell University Press.

Krause K., \& Williams, M. C. (Eds.). (1997a). Critical security studies: Concepts and cases. Minneapolis: University of Minnesota Press.

Krause, K. \& Williams, M. C. (1997b). From strategy to security: Foundations of critical security studies. In K. Krause \& M. C. Williams (Eds.), Critical security studies: Concepts and cases (pp. 33-59). Minneapolis: University of Minnesota Press.

Krause, K. \& Williams, M. C. (1997c). Preface: Toward critical security studies. In K. Krause \& M. C. Williams (Eds.), Critical security studies: Concepts and cases (pp. vii-xxi). Minneapolis: University of Minnesota Press.

Lisle, D. (2006). The global politics of contemporary travel writing. Cambridge: Cambridge University Press.

Mutimer, D. (Forthcoming, 2009). Critical security studies. In V. Mauer \& M. Dunn Cavelty (Eds.), Handbook of security studies. London: Routledge.

Mutimer, D. (2008). Review: Ken Booth, Theory of world security. Ethics and international Affairs, 22 (4), 429-430.

Salter, M. (2007). On exactitude in disciplinary science: A response to the network manifesto. Security Dialogue, 38(1), 113-122.

Sylvester, C. (2007). Anatomy of a footnote. Security Dialogue, 38(4), 547-558. 